\title{
Crohn's disease: The benefits of extensive surgery
}

\author{
BRUCE G WOLFF, MD
}

BG WOLFF. Crohn's disease: The benefits of extensive surgery. Can J Gastroenterol 1993;7(2):250-253. Crohn's disease is frequently discussed as a surgically incurable disease. Because of this, an atmosphere of surgical nihilism permeates many discussions about appropriate surgery for Crohn's disease. Even though minimal surgery is often most appropriate for certain situations, more extensive surgery clearly has a place in other situations. Among these situations are extensive perianal Crohn's disease with or without colonic involvement. Proctocolectomy and Brooke ileostomy in this setting has a much lower recurrence rate than ileorectostomy or diversion procedures. Rectovaginal fistulas frequently can be managed with less extensive surgery, but proctocolectomy is curative of this particular condition. More extensive surgery is indicated for toxic megacolon, as well as for children with Crohn's colitis who fail to thrive. There is considerable controversy about disease involvement at surgical margins before anastomosis; however, there is considerable data to support the practice of trying to achieve at least grossly free margins in patients with a single short segment of isolated Crohn's disease. While the fear of short bowel syndrome from radical resection remains, the thoughtful surgeon can appropriately tailor a more extensive operation in certain circumstances that may save the patient a quick reoperation or multiple future procedures in a misguided attempt to preserve dysfunctional bowel

Key Words: Crohn's disease, Margins of resection, Radical resection

\section{Maladie de Crohn : avantages de la chirurgie étendue}

La maladie de Crohn est souvent présentée comme une maladie inguérissable chirurgicalement. À cause de cela, le sujet est souvent ignoré dans le cadre de discussions sur la chirurgie appropriée dans la maladie de Crohn. Même si la chirurgie minimale est souvent la plus appropriée dans certains cas, une chirurgie

Associate Professor of Surgery, Mayo Medical School, Rochester, Minnesota, USA

Correspondence and Reprints: Dr BG Wolff, Mayo Clinic, 200 First Street SW, Rochester, MN 55905, USA
IXTY YEARS AFTER THE DESCRIP-
tion of regional ileitis or Crohn's disease, there has been relatively little progress in establishing an etiology for this frustrating and debilitating disease or of determining appropriate surgical management. While almost all surgeons agree on a more limited resection than in the past, radical resections are rarely performed. The question of disease-free margins and their association with decreased recurrence rates, together with the question of radical resection for Crohn's colitis remains unsettled and contested in the literature. In spite of the controversy, it is clear that many patients have benefited from limited and extensive surgery for Crohn's disease and it remains a question of applying the appropriate operation to the individual patient's disease.

In general, surgery is most advantageous in cases of Crohn's disease that are intractable to medical management. Chronic obstruction, enteroenteric fistulas, and chronic anemia from bleeding are also indications for elective surgical treatment of Crohn's disease. Perforation and toxic megacolon head the list of complications along with the rare occurrence of mas- 
plus libérale présente parfois très certainement des avantages. Parmi ces situations, mentionnons la maladie de Crohn périanale, avec ou sans atteinte colique. La proctocolectomie et l'iléostomie de Brooke dans ce contexte amènent un taux de récurrence bien moindre que l'iléorectostomie ou les procédures de détournement. Les fistules rectovaginales peuvent fréquemment être traitées par intervention moins étendue, mais la proctocolectomie traite cette atteinte en particulier. La chirurgie plus étendue est indiquée pour le mégacôlon toxique, de même que chez les enfants atteints de colite de Crohn qui ne progressent pas. Même si la controverse est grande à propos de l'atteinte inflammatoire au niveau des marges avant l'anastomose, de nombreux résultats pointent en direction d'interventions qui prévoient des marges macroscopiquement libres chez des patients atteints de maladie de Crohn sur un seul segment isolé et court. Bien que la crainte du syndrome de malabsorption par perte anatomique d'un segment du grêle nous hante encore, le chirurgien circonspect peut ajuster adéquatement une opération plus étendue selon les circonstances afin d'épargner au patient une nouvelle intervention précipitée ou des interventions à répétition rendues nécessaires si le chirurgien a voulu préserver une portion dysfonctionnelle de l'intestin.

sive hemorrhage for emergency operation. Failure to thrive and malnourishment is the primary indication for surgery in children.

Having stated these indications, the literature over the past 50 years indicates that: half the patients with limited involvement of Crohn's disease who undergo operation may never have a recrudescence; patients who do have a recrudescence may not necessarily need a further procedure and may have many years of a disease- and medication-free life preceding the recrudescence; the surgical mortality from operations of Crohn's disease is low; and the area of resection is largely nonfunctional from a nutritive standpoint.

\section{RADICAL RESECTIONS}

The surgical practice of performing a radical resection and indeed what constitutes marginal involvement with Crohn's disease has been the subject of debate for many years. In 1977, Bergman and Krause (1) reported their results with a radical resection of at least $10 \mathrm{~cm}$ of macroscopically and microscopically free margin on either side of a Crohn's lesion. After an observation time of 10.5 years in 186 patients, only $29 \%$ of patients undergoing a radical resection demonstrated a recurrence of Crohn's disease, whereas $84 \%$ of patients with a nonradical resection developed recurrence (1). This paper has been criticized as the radical and nonradical resections were carried out in two different hospitals. In 1985, even longer follow-up of these patients was provided in which the radical resections gave a lower recurrence rate $(31 \%)$, fewer reoperations and a better quality of life compared to those who underwent a nonradical resection (recurrence rate 83\%) (2).

Others have advocated an even larger margin of 15 to $20 \mathrm{~cm}$ of bowel above the involved area along with histologic examination of the margins during the operation (3). Nygaard and Fausa (4) reported an experience with radical versus nonradical resection and found a significantly lower rate of recurrence during the first postoperative year in radically resected (six of 25) patients than was found in nonradically resected (eight of 15) patients. Several others (5-7) found that extending resection proximally to an area that is microscopically normal does not lower the recurrence rate.

\section{HISTOLOGICAL MARGIN}

Microscopic involvement of the margins has been examined, with conflicting results. In one study from Norway (8), there was a $14 \%$ recurrence rate when the margins of resected intestine were free from disease, compared with a $66 \%$ rate when microscopic signs of the disease were present. In another study of 99 patients with Crohn's disease, of 75 patients with disease-free anastomotic margins, only $22 \%$ were reoperated on compared with a reoperation rate of $70 \%$ among the 24 patients who had involved anastomotic margins (9). The disease-free interval was also significantly longer (89 months versus 21 months) in patients with free anastomotic margins.

In a similar retrospective study of 67 patients from Sweden, recurrent disease developed in $36 \%$ of the patients whose resections did not have macroscopic evidence of Crohn's disease, whereas $38 \%$ of the patients with signs of Crohn's disease developed a clinical recurrence (10). This is supported by a 1987 study from France (11) of 58 patients with Crohn's disease who underwent resection. When patients with involved margins were compared with those without, the study found no statistically significant difference in recurrence rate, interval between primary surgery and reoperation at site of recurrent disease.

In our own 1983 study (12), we found an extremely high rate of recurrence in 39 patients who had microscopic evidence of disease at the anastomotic margin with recurrence documented at the anastomotic site. All of the margins in question were reviewed and were confirmed as having evidence of Crohn's disease on the original specimen. We felt that microscopically disease-free margins should be obtained from a patient with an isolated segment of Crohn's disease, but not at the cost of removing excessive amounts of normal small bowel. More recently, a similar study from the Cleveland Clinic (13) found no difference in recurrence rate between patients who had histological evidence of Crohn's disease and those who did not. This study confirmed an earlier study by Pennington et al (14). All of these studies suffer from the fact that they are not population based, and all for the most part have been performed in referral centres with the accompanying referral bias. All have been done as retrospective reviews and there are assumptions about recurrence that were erroneous.

In one study of 89 patients with Crohn's disease who had been treated by ileal resection and were followed prospectively (15), 73\% developed en- 
doscopic evidence of recurrent lesions just proximal to the anastomosis within one year, although only $20 \%$ of these patients had symptoms. Another prospective study closely followed Crohn's disease patients for recurrence (16). To date, 50 patients $(32 \%)$ have symptomatic disease while another 34 (22\%) have asymptomatic disease. Thus, the symptomatic recurrence rates at one and two years are 19 and $31 \%$ respectively while the total (symptomatic and asymptomatic) rates are 23 and $52 \%$, respectively. Patients with margins decreased recurrence rate of 10 to $15 \%$, as opposed to those who had a surgical margin less than $5 \mathrm{~cm}$. However, these data are preliminary and a final multivariate analysis will need to be made before any definite conclusions can be drawn.

Sachar (17) proposed that two factors seem to exert particularly strong influence on postoperative recurrence rates. One is the surgical procedure itself, with recurrences appearing earlier and more frequently after bowel anastomosis than after ileostomies. The second is the behaviour of the underly. ing disease, with the aggressive fistulizing form of Crohn's disease returning patients to surgery earlier than the more indolent obstructive form.

\section{CROHN'S COLITIS}

One area in which more extensive surgery, namely proctocolectomy, is effective, is for colonic Crohn's disease. Several studies (18-20) have shown that the recurrence rate after proctocolectomy is much lower than that for colectomy and ileorectal anastomosis. Segmental colectomy also has equal to or greater than $5 \mathrm{~cm}$ showed a a high recurrence rate for Crohn's colitis (21), but one can make the argument that this is at a cost of a permanent ileostomy and loss of normal bowel function. Treatment of perianal disease with temporary diversion has not been successful in our own series (22). Ileorectostomy clearly has a better chance of success if there is minimal or no perianal and rectal disease, if the patient has an adequate reservoir remaining after the anastomosis, and if the patient's sphincter function is good. There is also no evidence that proximal resection of bowel involved with Crohn's disease leads to amelioration of anorectal disease except on a temporary basis (23).

\section{TOXIC MEGACOLON OR FULMINANT COLITIS}

More extensive surgery for toxic megacolon clearly has a benefit in patients with known Crohn's colitis, who should undergo proctocolectomy with Brooke ileostomy as a single procedure. If there is doubt as to the diagnosis and distinction between ulcerative colitis and Crohn's colitis, then a subtotal colectomy with a Hartmann procedure or mucous fistula, as described by McLeod and associates (24), should be performed. Only in the rare instance of extreme dilation and friability of the bowel wall should the blow-hole procedure, popularized by Turnbull, be performed (25).

\section{PEDIATRIC SURGERY}

In one study of pediatric patients who underwent surgery for Crohn's disease during childhood (26), it was found that 15 of 16 children who had subtotal colectomy with ileostomy as a primary procedure have remained well on long term follow-up. In addition, an increase in growth rate was observed during the first year after operation in $89 \%$ of 40 children studied. Improved growth is clearly an early benefit of surgery in this group of patients. Six of seven patients had staged colonic resections with a primary anastomosis relapse, as did three of four patients given a loop ileostomy to divert fecal flow. In another study (27), 38 children with Crohn's colitis were followed after surgery, and $53 \%$ eventually underwent proctocolectomy. Again, in this group, resection of active intra-abdominal disease was not necessarily followed by resolution of perianal lesions, and defunctionalizing the rectum did not appear to alter or prevent the progression of perianal disease.

\section{CONCLUSIONS}

In summary, there are benefits for extensive surgery for Crohn's disease. particularly in Crohn's colitis with proctocolectomy and ileostomy yield. ing a much lower recurrence rate than subtotal colectomy and ileorectostomy or segmental colectomy. Proctocolectomy clearly has substantial benefits in a setting of toxic megacolon with Crohn's colitis. The data are less clear in dealing with small bowel resections, but when an isolated segment of Crohn's disease is present, there are enough data to support achieving clear margins on either side of the lesion if this does not involve extensive resection of normal small bowel. More extensive surgery in pediatric patients with Crohn's disease may lead to accelerated growth and a lower recurrence rate even though an ileostomy may be required.

Recurrence after surgical treatment. Scand J Gastroenterol 1979;12:577-84.

\section{REFERENCES}

1. Bergman L, Krause U. Crohn's disease: A long-term study of the clinical course in 186 patients. Scand J Gastroenterol 1977;12:937-44.

2. Krause U, Ejerblad S, Bergman L. Crohn's disease: A long-term study of the clinical course in 186 patients. Scand J Gastroenterol 1985;20:516-24.

3. Ihasz M, Mester E, Refi M. Experience in surgical management of Crohn's disease. Am J Proctol 1975;26:47-62.

4. Nygaard K, Fausa O. Crohn's disease:
5. Hardin CA, Friesen RH. Surgical treatment of regional enteritis. Am J Surg 1973;125:596-600.

6. Colcock BP. Operative technique in surgery for Crohn's disease and its relationship to recurrence. Surg Clin North Am 1973;53:375-80.

7. Glotzer DJ, Silen W. Surgical management of regional enteritis. Gastroenterology 1971;61:751-6.

8. Karesen R, Serch-Hanssen A,
Thoresen BO, Hertzberg J. Crohn's disease: Long-term results of surgical treatment. Scand J Gastroenterol 1981; 16:57-64.

9. Oube S, Heyen F, Beliveau D. Crohn's disease and surgery: A plea for disease free margins. Poster presentation at the American Society of Colon and Rectal Surgeons meeting, Anaheim, California, June 12-17, 1988.

10. Heuman R, Boeryd B, Bolin T, Sjodahl $R$. The influence of disease at the margin of resection on the outcome of 
Crohn's disease. Br J Surg 1983;70:519-21.

11. Adloff M, Arnaud JP, Ollier JC. Does the histologic appearance at the margin of resection affect the postoperative recurrence rate in Crohn's disease? Am Surg 1987;53:543-6.

12. Wolff BG, Beart RW, Frydenberg HB, et al. The importance of disease-free margins in resections for Crohn's disease. Dis Colon Rectum 1983;26:239-43.

13. Kotanagi H, Kramer K, Fazio VW, Petras RE. Do microscopic abnormalities at resection margins correlate with increased anastomotic recurrence in Crohn's disease? Retrospective analysis of 100 cases. Dis Colon Rectum 1991;34:909-16.

14. Pennington L, Hamilton SR, Bayless TM, Cameron JL. Surgical management of Crohn's disease: Influence of disease at margin of resection. Ann Surg 1980;192:311-7.

15. Rutgeerts P, Geboes K, Vantrappen G, Beyls J, Kerremans R, Hiele M. Predictability of the postoperative course of Crohn's disease. Gastroenterol 1990;99:956-63.
16. Wolff BG, McLeod R. A randomized controlled trial to detemine the effectiveness of 5'-aminosalicylic acid ( $5^{\prime}$-ASA) in preventing or delaying the recurrence of Crohn's disease. (In press)

17. Sachar DB. Patterns of postoperative recurrence in Crohn's disease. Scand J Gastroenterol 1990;172:35-7.

18. Goligher JC. The long-term results of excisional surgery for primary and recurrent Crohn's disease of the large intestine. Dis Colon Rectum 1985;28:51-5.

19. Farnell MB, van Heerden JA, Beart RW, Weiland LH. Rectal preservation in nonspecific inflammatory disease of the colon. Ann Surg 1980;192:249-53.

20. Buchmann P, Weterman IT, Keighley MRB, Pena SA, Allan RN,

Alexander-Williams J. The prognosis of ileorectal anastomosis in Crohn's disease. Br J Surg 1981;68:7-10.

21. Longo WE, Ballantyne GH, Cahow CE. Treatment of Crohn's colitis. Segmental or total colectomy? Arch Surg 1988;123;588-90.

22. McIlrath DC. Diverting ileostomy or colostomy in the management of Crohn's disease of the colon. Arch Surg 1971;103:308-10.

23. Wolff BG, Culp CE, Beart RW, Ilstrup DM, Ready RL. Anorectal Crohn's disease. A long-term perspective. Dis Colon Rectum 1985;28;709-11.

24. Carter FM, McLeod R, Cohen Z. Subtotal colectomy for chronic ulcerative colitis: Complications related to the rectal remnant. Dis Colon Rectum 1991;34:1005-9.

25. Turnbull RB Jr, Hawk WA, Weakley FL. Surgical treatment of toxic megacolon: Ileostomy and colostomy to prepare patients for a colectomy. Am J Surg 1971;122:325-31

26. Davies G, Evans CM, Shand WS, Walker-Smith JA. Surgery for Crohn's disease in childhood: Influence of site of disease and operative procedure on outcome. Br J Surg 1990;77:891-4.

27. Orkin BA, Telander RL. The effect of intra-abdominal resection or fecal diversion on perianal disease in pediatric Crohn's disease. J Pediatr Surg 1985;20:343-7. 


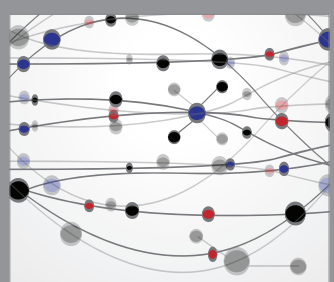

The Scientific World Journal
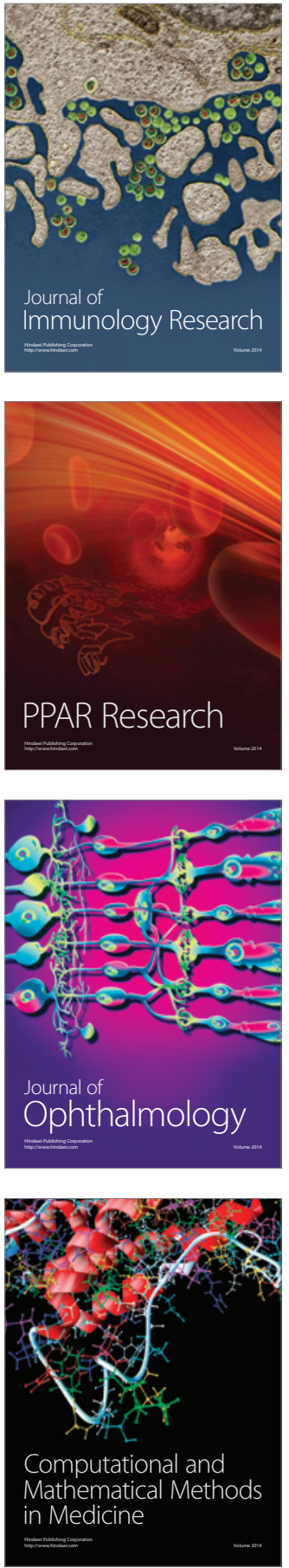

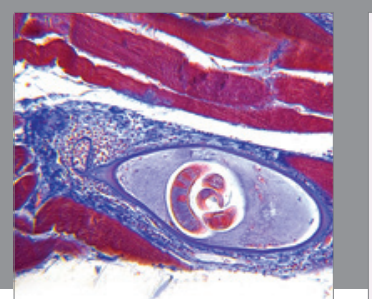

Gastroenterology Research and Practice

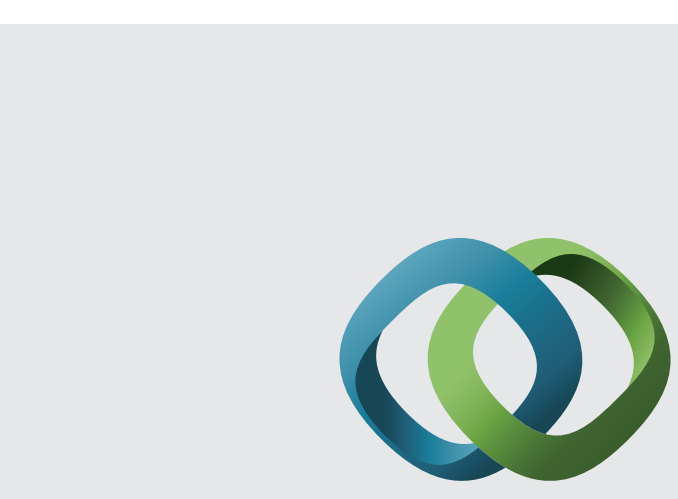

\section{Hindawi}

Submit your manuscripts at

http://www.hindawi.com
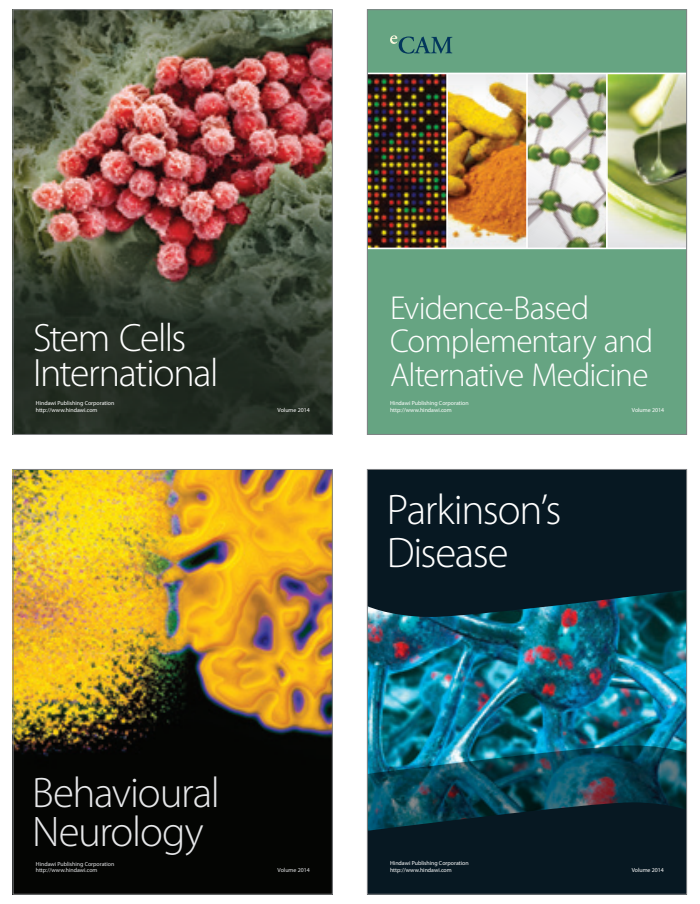
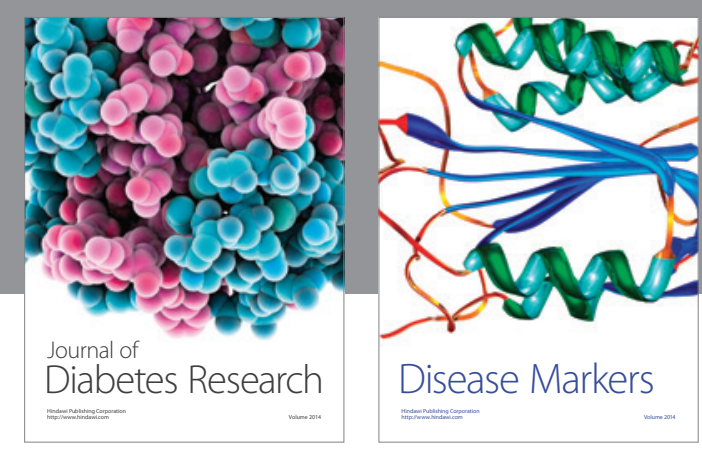

Disease Markers
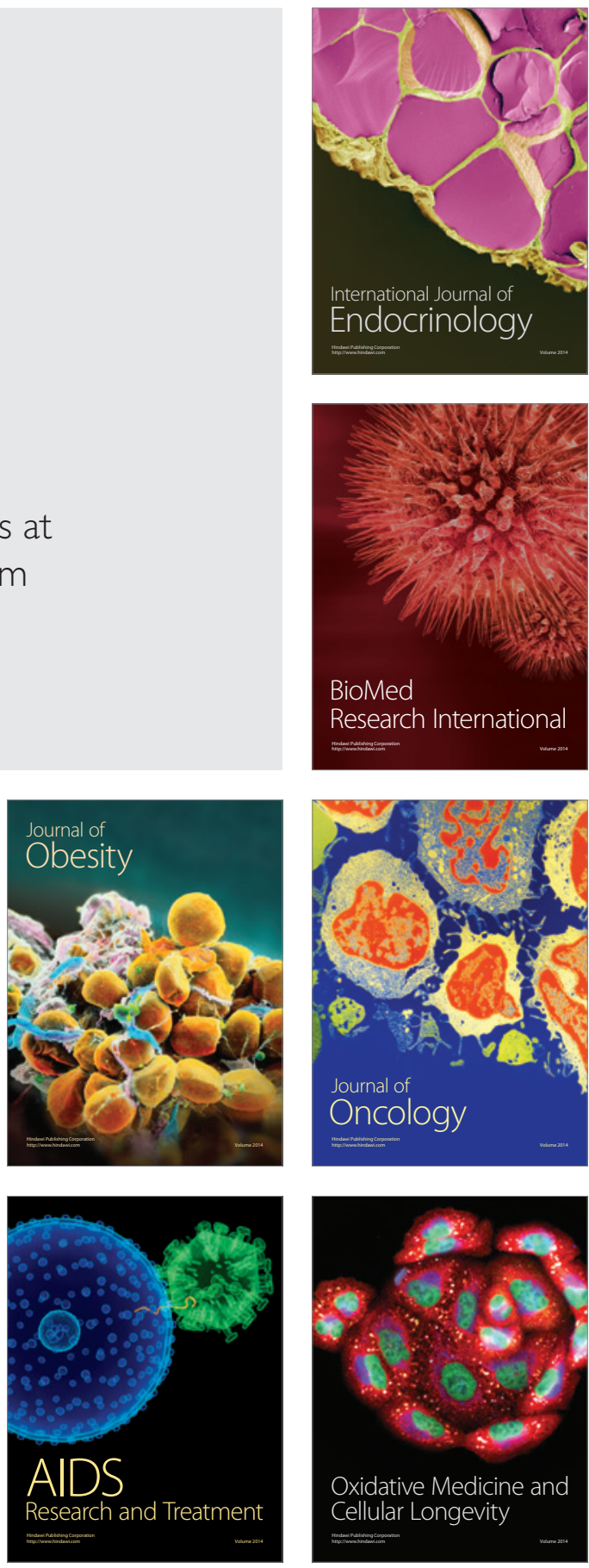